\title{
Stratification, Partisanship and Love
}

\author{
Lawrence T. Nichols
}

Published online: 24 February 2010

(C) Springer Science+Business Media, LLC 2010

In this issue we offer a set of papers that share concerns about inclusiveness and opportunity, as these apply both to particular groups within sociology and to established practices within subfields of the discipline. Gender, race and nationality take turns on center stage in these analyses. There is also a compassionate examination of the situation of one often neglected minority group, namely graduate students, who are of course the key to the discipline's future within academia.

Elizabeth Monk-Turner and Becki Fogerty begin the conversation with an examination of productivity differences as affected by local workplace cultures. They are primarily concerned about the situation of women in sociology, and especially those building careers in what the authors characterize as "chilly" environments. Their findings also point to significant experiential differences in the contexts of ranked and unranked departments across the United States.

Roger Clark and Ryan Dandrea likewise focus on gender effects, in particular what they describe as the "eclipsing" of women in sociological theory. Building on earlier work by Kathryn Ward and Linda Grant, they undertake a longitudinal study of women's participation and recognition in three conventional outlets for theorizing. Their findings include both positive and negative results, and they reflect also on complications in the analysis arising from women's choices of non-conventional outlets for theoretical work.

Stephen Poulson and Colin Campbell shift the focus of the conversation to the subfield of the sociology of religion. These authors are especially concerned with what might be regarded as an excessively inward orientation of scholarly work that is also self-reinforcing- a pattern they sum up in the phrase "institutional parochialism." Poulson and Campbell inquire in particular about the relative percentages of published articles on Muslim and non-Western groups that appear in two leading journals in the periods before and after the 9/11/01 attacks in New York City. The authors touch again on the theme of gender, and conclude by

L. T. Nichols $(\square)$

Division of Sociology and Anthropology, West Virginia University, Morgantown, WV, USA

e-mail: Larry.Nichols@mail.wvu.edu 
suggesting that the observed parochialism in the sociology of religion might be an important indicator of a more widespread inwardness in the discipline.

Jack Niemonen highlights the issue of race and develops a detailed critique of "whiteness studies" based on an examination of more than two hundred journal articles in this area. Orienting his analysis in terms of recent proposals for "public sociology," Niemonen targets what he regards as an excessively partisan orientation, or a "hermeneutics of suspicion." He concludes that the "whiteness" approach contradicts public sociology's ideals, as formulated in Michael Burawoy's model that affirms the value of "professional" sociology.

Kevin Haggerty rounds out the discussion with his own version of "tough love" for graduate students. Focusing his critical gaze on misunderstandings and mythologies surrounding the apprenticeship period, Haggerty offers insight into the requirements of professional success, including mentoring, networking, writing and prioritizing. Such counsel may prove particularly valuable for those who aspire to careers in research-oriented universities in Canada and the U.S. 